\title{
Genetic and morphometric divergence in the Garnet-Throated Hummingbird Lamprolaima rhami (Aves: Trochilidae)
}

Luz E. Zamudio-Beltrán ${ }^{1,2}$ ， Blanca E. Hernández-Baños ${ }^{\text {Corresp. } 2}$

1 Posgrado en Ciencias Biológicas, Universidad Nacional Autónoma de México, Ciudad de México, Mexico

2 Departamento de Biología Evolutiva, Facultad de Ciencias, Museo de Zoología, Universidad Nacional Autónoma de México, Ciudad de México, Mexico

Corresponding Author: Blanca E. Hernández-Baños

Email address: behb@ciencias.unam.mx

Cloud forests are one of the most endangered ecosystems in the Americas, as well as one of the richest in biological diversity in the world. The species inhabiting these forests are susceptible to environmental changes and characterized by high levels of geographic structure. The Garnet-Throated Hummingbird, Lamprolaima rhami, mainly inhabits cloud forests, but can also be found in other habitats. This species has a highly restricted distribution in Mesoamerica, and five disjunct regions have been delimited within the current geographic distribution of the species from Mexico to Honduras. According to variation in size and color, three subspecies have been described: L. r. rhami restricted to the Mexican highlands and Guatemala, L. r. occidentalis distributed in Guerrero (Mexico), and L. r. saturatior, distributed in the highlands from Honduras and El Salvador. We analyzed the levels of geographic structure in L. rhami and its taxonomic implications. We used mitochondrial and nuclear DNA to analyze genetic variation, demographic history, divergence times, reconstructed a multilocus phylogeny, and performed a species delimitation analyses. We also evaluated morphological variation in 208 specimens. We found high levels of genetic differentiation in three groups, and significant variation in morphological traits corresponding with the disjunct geographic populations. L. rhami presents population stability with the highest genetic variation explained by differences between populations. Divergence time estimates suggest that $L$. rhami split from its sister group around 10.55 million years ago, and the diversification of the complex was dated ca. $0.207 \mathrm{Mya}$. The hypotheses tested in the species delimitation analyses validated three independent lineages corresponding to three disjunct populations. This study provides evidence of genetic and/or morphometric differentiation between populations in the $L$. rhami complex where four separate evolutionary lineages are supported: 1) populations from the Sierra Madre Oriental and the highlands of Oaxaca (rhami), 2) populations from the highlands of Guerrero (occidentalis), 3) populations from the highlands of Chiapas and Guatemala (this is a non-previously proposed potential taxon: tacanensis), and 4) 
populations from the highlands of Honduras and El Salvador (saturatior). The main promoters of the geographic structure found in the L. rhami complex are likely the Isthmus of Tehuantepec as a geographic barrier, isolation by distance resulting from habitat fragmentation, and climatic conditions during the Pleistocene. 
1 Genetic and morphometric divergence in the Garnet-Throated Hummingbird Lamprolaima

2 rhami (Aves: Trochilidae).

3

4 Luz Estela Zamudio-Beltrán ${ }^{1,2}$, Blanca Estela Hernández-Baños ${ }^{2}$

5

6 1Posgrado en Ciencias Biológicas, Universidad Nacional Autónoma de México, Mexico City,

7 Mexico

8 2Museo de Zoología, Departamento de Biología Evolutiva, Facultad de Ciencias, Universidad

9 Nacional Autónoma de México, Mexico City, Mexico.

10

11 Corresponding Author:

12 Blanca Estela Hernández-Baños ${ }^{\mathrm{a}}$

13 E-mail address: behb@ciencias.unam.mx 
15 Abstract

16

17 Cloud forests are one of the most endangered ecosystems in the Americas, as well as one of

18 the richest in biological diversity in the world. The species inhabiting these forests are

19 susceptible to environmental changes and characterized by high levels of geographic

20 structure. The Garnet-Throated Hummingbird, Lamprolaima rhami, mainly inhabits cloud

21 forests, but can also be found in other habitats. This species has a highly restricted

22 distribution in Mesoamerica, and five disjunct regions have been delimited within the

23 current geographic distribution of the species from Mexico to Honduras. According to

24 variation in size and color, three subspecies have been described: L. r. rhami restricted to

25 the Mexican highlands and Guatemala, L. r. occidentalis distributed in Guerrero (Mexico),

26 and L. r. saturatior, distributed in the highlands from Honduras and El Salvador. We

27 analyzed the levels of geographic structure in L. rhami and its taxonomic implications. We

28 used mitochondrial and nuclear DNA to analyze genetic variation, demographic history,

29 divergence times, reconstructed a multilocus phylogeny, and performed a species

30 delimitation analyses. We also evaluated morphological variation in 208 specimens. We

31 found high levels of genetic differentiation in three groups, and significant variation in

32 morphological traits corresponding with the disjunct geographic populations. L. rhami

33 presents population stability with the highest genetic variation explained by differences

34 between populations. Divergence time estimates suggest that L. rhami split from its sister

35 group around 10.55 million years ago, and the diversification of the complex was dated ca.

$36 \quad 0.207$ Mya. The hypotheses tested in the species delimitation analyses validated three

37 independent lineages corresponding to three disjunct populations. This study provides 
38 evidence of genetic and/or morphometric differentiation between populations in the $L$.

39 rhami complex where four separate evolutionary lineages are supported: 1) populations

40 from the Sierra Madre Oriental and the highlands of Oaxaca (rhami), 2) populations from

41 the highlands of Guerrero (occidentalis), 3) populations from the highlands of Chiapas and

42 Guatemala (this is a non-previously proposed potential taxon: tacanensis), and 4)

43 populations from the highlands of Honduras and El Salvador (saturatior). The main

44 promoters of the geographic structure found in the L. rhami complex are likely the Isthmus

45 of Tehuantepec as a geographic barrier, isolation by distance resulting from habitat

46 fragmentation, and climatic conditions during the Pleistocene.

47

\section{Introduction}

Cloud forests are one of the most threatened and biodiverse habitats in the world

50 51

52 53
(Hamilton, 1995; Mulligan, 2010). In Mesoamerica, the transition zone between the Nearctic and Neotropical regions (Ríos-Muñoz, 2013; Morrone, 2014), cloud forests are restricted to forest habitats between 600 and $3000 \mathrm{~m}$ above sea level (Foster, 2001). Several studies have tried to describe the evolutionary processes that have shaped the enormous diversity observed in cloud forests, concluding that species show high levels of isolation and population differentiation when compared to lowland forest habitats that may be more geographically interconnected (de Barcellos \& Voltolini, 1995; Ataroff \& Rada, 2000; Ornelas et al., 2013). However, studies at the population level, including a large sampling effort, are crucial to describe intraspecific variation more precisely (Bonaccorso et al., 2008; McCormack et al., 2008; Arbeláez-Cortés \& Navarro-Sigüenza, 2013). 

recognizing new species in cloud forests (González-Rodríguez et al., 2004; Cortés-

Rodríguez et al., 2008; Ornelas et al., 2010; González et al., 2011). However, the fast pace at which these forests are disappearing due to anthropogenic causes is one of the multiple reasons to promote the study of the evolutionary processes taking place in this particularly diverse ecosystem (Olander et al., 1998; Martínez-Morales, 2005).

The Trochilidae family includes several species complexes that have been excellent models for evolutionary studies (Bleiweiss, 1998a; McGuire et al., 2007; McGuire et al., 2014), though to date, only a few of these studies focus on species inhabiting cloud forests (Bleiweiss, 1998b; Chaves et al., 2007; Cortés-Rodríguez et al., 2008; Chaves \& Smith, 2011). The Garnet-Throated Hummingbird, Lamprolaima rhami, (Lesson, 1839) has a restricted Mesoamerican distribution; it can inhabit tropical upland forests, pine-oak

72 forests and scrub, but primarily occupies cloud forest habitats, within an altitudinal range

73 between 1200 and 3000 m (Howell \& Webb, 1995; Schuchmann \& Boesman, 2018). It is

74 considered a relatively sedentary species, though individuals do show some seasonal 75 movement to higher elevations during the breeding season (Schuchmann \& Boesman, 76 2018). areas: 1) Sierra Madre Oriental (Puebla to Veracruz) and the northern highlands of Oaxaca 79 (Mexico), 2) the highlands of Guerrero, in the Sierra Madre del Sur (Mexico), 3) the 80 southern highlands of Oaxaca, in the Sierra de Miahuatlan (Mexico), 4) the highlands of 81 Chiapas (Mexico) and Guatemala, and 5) the highlands of Honduras and El Salvador, in 82 Central America. Three subspecies have been recognized based on differences on size and 
83 color: L. r. rhami, L. r. occidentalis, and L.r. saturatior. L. r. rhami is restricted to the

84 highlands of central and southern Mexico (in the states of Puebla, Veracruz, Oaxaca and

85 Chiapas) and the Guatemala highlands (Lesson, 1839; Peters, 1945). L. r. occidentalis

86 corresponds to populations found in a restricted patch in Guerrero, southwestern Mexico

87 (Phillips, 1966). L. r. saturatior is found in the highlands of Honduras and El Salvador

88 (Griscom, 1932; Peters, 1945). Schuchmann and Boesman (2018) considered that L. rhami

89 possibly belongs to the genus Basilinna, and argued that occidentalis and saturatior are not

90 suitable for subspecific recognition, proposing them only as races, considering that traits

91 used in their descriptions are either age-dependent or clinal in character (color and size

92 variation).

93 Considering its restricted distribution and frequent occupation of highly fragmented

94 forests with unique bioclimatic characteristics, L. rhami represents an interesting model to

95 assess evolutionary hypotheses about geographic structure and populations dynamics with

96 conservation implications. Hence, the main objectives of this paper are to: 1) evaluate the

97 genetic and morphometric variation of the Lamprolaima rhami complex by comparing

98 individuals from the five regions where it is distributed, 2) describe the phylogenetic

99 relationships within L. rhami using a multilocus dataset (nuclear and mitochondrial DNA),

100 and 3) propose a hypothesis of its evolutionary history. Based on the characteristics of

101 cloud forest and the site fidelity of this hummingbird species, we expect to find high levels

102 of genetic structure supported by congruence in morphological variation within the $L$.

103 rhami complex. Thus, phylogenetic discontinuities and spatial disjunction are expected

104 rather than phylogenetic continuity and lack of spatial disjunction. 
106 Methods

107 Taxon sampling and sequencing.

108 We obtained tissues from 54 individuals of L. rhami from 14 localities across most of

109 its geographic range (Table S1, Fig. 1, using field collecting permit from Instituto Nacional

110 de Ecología, SEMARNAT: FAUT-0169). We defined five groups a priori to evaluate genetic

111 and morphological variation among the five allopatric regions where the species occurs: 1 )

112 the Sierra Madre Oriental (SMO), 2) the highlands of Guerrero (GRO), 3) the Sierra of

113 Miahuatlan in Oaxaca (MIA), 4) the highlands of Chiapas and Guatemala (CHIS), and 5) the

114 region in Central America comprising the highlands of Honduras and El Salvador (CA).

115 Tissue samples were obtained for four geographic groups (excluding the CA group) from

116 the following collections: “Museo de Zoología Alfonso L. Herrera” (Universidad Nacional

117 Autónoma de México), Museum of Natural Science (Lousiana State University), and

118 Museum of Vertebrate Zoology (University of California, Berkeley).

DNA was extracted using the DNAeasy ${ }^{\mathrm{TM}}$ kit (Qiagen Inc., Valencia, CA, USA),

120 following the manufacturer's protocols. To evaluate genetic variation in the complex, two

121 mitochondrial markers were obtained from the 54 samples (Control Region, CR; and

122 subunits 6 and 8 from ATPase gene, ATPase $6 \& 8$ ). To evaluate phylogenetic relationships

123 and for species delimitation analyses between groups, two additional mitochondrial

124 markers and four nuclear regions were surveyed in a subsample of 31 individuals (NADH

125 dehydrogenase subunit 2, ND2; NADH dehydrogenase subunit 4, ND4; the 7th intron of the

126 beta fibrinogen gene, $B F i b$, the regions between exons 4 and 5 of the Muscle Skeletal

127 Receptor Tyrosine Kinase gene, MUSK; a segment comprising the end of exon 6 and the

128 beginning of exon 8 of the Ornithine Decarboxylase gene, $O D C$, and intron 5 of adenylate 
129 kinase gene, $A K 1$ ). We included sequences from the same molecular markers, available in

130 GenBank for Eugenes fulgens, E. spectabilis, and Tilmatura dupontii, to serve as outgroups

131 (McGuire et al., 2007; Zamudio-Beltrán \& Hernández-Baños, 2015).

132 We amplified these molecular markers via polymerase chain reaction (PCR) using

133 specific primers and protocols (Table S3). Reactions contained 10X buffer (1.25 $\mu \mathrm{L}), 10 \mathrm{mM}$

$134 \mathrm{dNTP}(0.19 \mu \mathrm{L}), 50 \mathrm{mM} \mathrm{MgCl} 2(0.38 \mu \mathrm{L}), 10 \mu \mathrm{M}$ of each primer $(0.25 \mu \mathrm{L}), 0.1 \mu \mathrm{L}$ of Taq

135 (INVITROGEN), and $0.5 \mu \mathrm{L}$ of genomic DNA (12.5 $\mu \mathrm{L}$ total volume). PCR products were

136 visualized on a $1 \%$ agarose gel, and DNA sequencing was performed by the High-

137 Throughput Genomics Unit Service of the University of Washington. We edited and aligned

138 chromatograms with Sequencher v4.8 (GeneCodes Corporation, Ann Arbor, MI). All

139 sequences were deposited in GenBank under accession numbers \#\#\#\#. Multilocus

140 alignment can be found in FigShare (https://figshare.com/s/14d2a747c825fba5f35d).

141

142

Population structure.

143

To evaluate the number of haplotypes and their relationships, a statistical

144 parsimony haplotype network was constructed for the concatenated dataset of

145 mitochondrial markers (CR and ATPase $6 \&$ 8), using the program TCS v1.21 (Clement et

146 al., 2000).

147 To analyze genetic diversity and genetic structure, we obtained values of haplotype 148 diversity, nucleotide diversity, mean number of pairwise differences, and population $F_{S T}$

149 values. These analyses were performed with 1000 replicates, using the program Arlequin

150 v3.11 (Excoffier et al., 2005). Using the same program, we conducted an analysis of

151 molecular variance (AMOVA; Excoffier et al., 1992) to detect structure between populations 
152 based on comparisons between geographically defined groups. According to our results,

153 regions on both sides of the Isthmus of Tehuantepec were also evaluated (IT, east and

154 west).

155 To evaluate the isolation by distance among geographic regions, we performed a

156 Mantel Test with 1000 iterations, comparing matrices of genetic and geographic distances,

157 using the program zt v1.1 (Bonnet \& de Peer, 2002). Statistical analyses were not

158 performed in the MIA group because of limited number of samples ( $n=2)$, but were

159 considered in haplotype networks and phylogenetic analyses.

160

161

Demographic analyses.

162 To evaluate demography and population stability, we obtained Tajima's $D$ and Fu's

163 Fs values, in Arlequin v2.11 (Excoffier et al., 2005), with 1000 replicates (mtDNA database).

164 Using the same program, parameters, and database, we further evaluated the historical 165 demography of each group under an expansion model with a MISMATCH distribution test

166 and estimated its significance with the raggedness index (Slatkin \& Hudson, 1991; Rogers \&

167 Harpending, 1992; Harpending, 1994). To analyze variation in effective population size

168 over time, we used Bayesian skyline plots (BSP; Drummond et al., 2005) performed in

169 BEAST v1.6.0 (Drummond \& Rambaut, 2007), with 10 million steps for mtDNA, using a

170 mean rate of 0.023 substitutions per site per lineage per million years (s/s/l/My), under

171 Control Region and ATPase estimates (Lerner et al., 2011).

172

173 Evolutionary Models and Phylogenetic analyses. 
174 For each molecular marker (mtDNA and nuclear DNA), we calculated the

175 evolutionary model that best fit the data based on the Akaike Information Criterion AIC

176 (Akaike, 1987) using jModelTest 0.1.1 (Posada, 2008). We performed a phylogenetic

177 reconstruction using the Bayesian Inference (BI) approach in Mr. Bayes v3.0 (Huelsenbeck

178 \& Ronquist, 2002). We assigned different evolutionary models to each gene partition. We

179 ran four simultaneous chains for each Monte Carlo Markov Chain analysis for 50 million

180 generations, sampling every 1000 generations. The results were visualized to ensure ESS

181 (effective sample sizes) values higher than 200, and the burn-in value was determined

182 using Tracer v1.6.0 (Rambaut et al., 2013). The initial 20\% of generations were eliminated.

183 The remaining trees were used to construct a majority rule consensus tree with posterior

184 probability distributions, which was visualized using the program FigTree v1.2.3

185 (http//tree.bio.ed.ac.uk/software/figtree/).

186

187

Morphological variation.

188 To examine morphological variation between groups of L. rhami, we took five

189 measurements from 208 voucher specimens (Table S2) corresponding to four of the five

190 geographic groups defined a priori (SMO, GRO, CHIS, CA). These specimens were available

191 from the following collections: Museo de Zoología “Alfonso L. Herrera” (MZFC, UNAM),

192 Museum of Comparative Zoology (MCZ), American Museum of Natural History (AMNH),

193 Donald R. Dickey Bird and Mammal Collection (BMC), and the Moore Lab of Zoology (MLZ).

194 Measurements for bill length (from the base to the tip of the upper mandible), bill width

195 (width at the nostrils), bill depth (from the upper mandible to the base of the bill at the

196 nostrils), and wing chord (distance from the carpal joint to the tip of the longest primary) 
197 were taken with a dial calliper with a precision of $0.1 \mathrm{~mm}$, while tail length (distance from

198 the uropigial gland to the tip of the longest rectrix) was determined with a milimetric ruler.

199 A single observer took all measurements. Subsets of individuals were measured twice to

200 confirm consistency between measurements using correlation coefficients obtained in

201 STATISTICA v7 (StatSoft, 2004). When variation among measurements was low or null, all

202 voucher specimens were measured once and these values were used in further analyses. To

203 test the normality of our data, we performed a Lilliefors (Kolmogorov-Smirnov) test using

204 the R package Nortest v1.0-4 (Gross \& Liges, 2015). This test was conducted with raw and

205 log-transformated data. Since the data were not normally distributed, a Wilcoxon/Mann-

206 Whitney test (Bauer, 1972) was performed to evaluate differences between males and

207 females. To evaluate differences among groups, and after confirming differences among

208 sexes, we conducted two sets of Kruskall-Wallis tests (Hollander \& Wolfe, 1973) to

209 compare: 1) geographic groups (SMO, GRO, CHIS, CA), and 2) groups separated by the

210 Isthmus of Tehuantepec (east, west). All tests were conducted for each variable, treating

211 males and females separately. Statistical analyses were performed using RStudio v.1.1.447

212 (RStudio Team, 2016).

213

214 Species delimitation and divergence times

215 According to the results, we assess the limits between different groups based on: 1)

216 disjunct populations (groups by geographic region: SMO, GRO, MIA, CHIS), 2) phylogroups

217 (SMO/MIA, GRO, CHIS), and 3) groups separated by the Isthmus of Tehuantepec (east:

218 SMO/MIA/GRO, and west: CHIS). We used the command line of coalescent approach

219 implemented in Bayesian Phylogenetics and Phylogeography software (BP\&P v3.4, Rannala 
220 \& Yang, 2003; Yang \& Rannala, 2010). This method uses the multispecies coalescent model

221 (MSC) to compare different models of species delimitation (Yang and Rannala, 2010; Rannala

222 and Yang, 2013) and species phylogeny (Yang and Rannala, 2014; Rannala and Yang, 2017) in a

223 Bayesian framework, accounting for incomplete lineage sorting due to ancestral polymorphism

224 and gene tree-species tree discordance. We used the concatenated data set of eight molecular

225 markers (mt DNA and nuclear DNA), but mitochondrial markers were treated as one locus,

226 so the total number of this parameter was set to nloci=5. To confirm consistency between

227 runs, we performed multiple analyses using algorithms 0 and 1 (0: species tree given as

228 fixed, 1: species tree given treated as the guide tree), selecting different seed number

229 between runs and changing finetune parameters ( $\varepsilon$, algorithm prior), as suggested by Yang 230 and Rannala (2010). After confirming consistency between runs, the subsequent analyses

231 were performed according to species delimitation using a user-specified guide tree

232 (speciesdelimitation $=1$, speciestree $=0$ ), with values of $\varepsilon=5$. The analyses were conducted

233 using parameter finetune $=1$, which allows the program to make automatic adjustments to

234 prior parameters. Because different values of $\theta$ (ancestral population size, the product of

235 effective population size $\mathrm{N}$ and mutation rate $\mu$ per site) can result in different posterior

236 probabilities for the same guide tree (Leaché \& Fujita, 2010; Yang, 2015), we used three

237 different values: 1 ) low $\theta$ priors (0.0001, IG: 3, 0.0002), 2) medium $\theta$ priors (0.001, IG: 3 ,

238 0.002), and 3) high $\theta$ priors (0.01, IG: 3, 0.02). The inverse gamma prior to $\tau$ (species

239 divergence times) was set to tauprior $=3,0.03,1.5 \%$ of sequence divergence. Each analysis

240 was run with the reversible-jump Markov chain Monte Carlo algorithm (rjMCMC) for 100

241 thousand generations, sampling every 5 , and discarding 30 thousand generations as burn242 in. 
244 independent groups based on full evidence (phylogroups: SMO/MIA, n=12; GRO, n=9; CHIS,

$245 \mathrm{n}=10$ ). We used the concatenated data set (mt DNA and nuclear DNA) that included data

246 from Eugenes fulgens, E. spectabilis, and Tilmatura dupontii as outgroups. For each

247 partition, we assigned the previous selected evolutionary model. This analysis was

248 performed using StarBeast (*Beast; Heled \& Drummond, 2010). We employed an

249 uncorrelated lognormal relaxed clock and a Yule process speciation model to model the

250 tree prior. We assigned a calibration node based on a secondary calibration obtained for

251 the split between the "Mountain Gems" clade (L. rhami, E. fulgens, and E. spectabilis) and

252 “Bees” clade (T. dupontii; 12.5 Mya; McGuire et al., 2014). We incorporated mean

253 substitution rates reported previously (ATPase 6 and 8, ND2, ND4: Pacheco et al., 2011; CR:

254 Lerner et al., 2011; AK1, BFib, MUSK, ODC: McGuire et al., 2014). Three independent

255 analyses were run for 30 million generations, sampling every 1000 . The log and tree files

256 from each analysis were combined in LogCombiner, and visualized in Tracer to confirm

257 convergence and ensure acceptable ESS values (ESS>200). We discarded the first 15\% of

258 trees as burn-in. We used TreeAnnotator v1.8.2 (Rambaut \& Drummond, 2007) to

259 summarize trees as a maximum clade credibility tree, and to obtain mean divergence times

260 with 95\% highest posterior density intervals. The resulting tree was visualized in FigTree

$261 \quad$ v.1.2.3.

262

263 Results

264 Genetic diversity and population structure. 
We obtained a concatenated dataset of 1402 bp for 54 individuals (527 bp of CR and

$266875 \mathrm{bp}$ of ATPase 6 \& 8). The complementary dataset of five molecular markers for 31

267 individuals included 875 bp of ATPase 6 and 8, 527 bp of CR, 918 bp of ND2, 521 bp of ND4,

$268758 \mathrm{bp}$ of BFib, $559 \mathrm{bp}$ of MUSK, $495 \mathrm{bp}$ of ODC, and $416 \mathrm{bp}$ of AK1. The initial dataset

269 included 33 haplotypes (24 found with CR and 15 with ATPase 6 \& 8). Estimates of

270 haplotype and nucleotide diversity are presented in Table 1. Overall, high haplotype

271 diversity and low nucleotide diversity were observed within groups (SMO, GRO, CHIS).

272 The mtDNA network revealed significant population structure within the L. rhami

273 complex (Fig. 1). There was a clear separation between populations on either side of the IT,

274 which were separated by twelve mutational steps, while individuals of GRO were closely

275 linked to those of the SMO. In general, the most frequent haplotype was present in

276 populations from the Sierra Madre Oriental group (SMO). Haplotypes from GRO tended to

277 separate from the main haplotype. In Table $2, F_{S T}$ values confirm high levels of geographic

278 structure between regions. This further translates into a significant correlation between

279 the genetic distance and the geographic distance matrices, according to the Mantel test,

280 thus suggesting isolation by distance between groups $(r=0.87, p<0.005)$.

281

AMOVA results indicated that the highest genetic variation was observed among

282 rather than within populations, with similar percentages when grouping populations

283 according to geographic groups or on either side of the IT: $76.41 \%$ and $78.74 \%$

284 respectively $(P<0.0001$, Table 3$)$.

285

286

Demographic analyses 

to ambiguous results. The occurrence of historical population expansion was supported by negative and significant values of neutrality tests (Tajima's $D$ and Fu's $F s$ ), except for Tajima's D statistic in SMO and GRO groups (Table 1). A mismatch distribution unimodal curve was recovered for CHIS population, but no significant values of the raggedness index 292 indicated possible demographic expansion in all populations, as curves under the expansion model did not deviate from a unimodal distribution. BSP estimates revealed that effective population size was flat across time for GRO. This pattern was also found for CHIS,

295 however, the higher posterior density low interval suggested a growing demographic 296 tendency, and a subtle demographic expansion was recovered in SMO population (Fig. 2).

297

298

Evolutionary models and Phylogenetic analyses.

We obtained a concatenated dataset of $5069 \mathrm{bp}$. The best-fit models for each molecular marker were as follows: HKY (MUSK), HKY+I (ATPase 6 and 8, ND4), HKY+G (AK1), HKY+I+G (CR), TNR+G (ND2), TPM3uf (ODC), and TPM2uf+I (BFib). Phylogenetic relationships using the multilocus dataset resulted in one main monophyletic group corresponding to individuals from west of the IT (PP > 0.95, Fig. 3: Bayesian Inference). Most individuals from east of the IT were grouped into two well-supported separate clades, but no resolution was recovered for three individuals from this region. Moreover, one wellsupported clade included most individuals from GRO group from west of the IT, with the 307 rest of individuals merged in a polytomy with individuals from SMO region. 
311 females in all variables (Table S4). General comparisons between geographic groups

312 resulted in significant differences in all variables for both males and females, while

313 comparisons between groups separated by the Isthmus of Tehuantepec showed significant

314 differences in bill width $\left(\chi^{2}=6.3669, p=0.01163\right)$ and wing chord $\left(\chi^{2}=8.0642, p=\right.$

315 0.004515) for males; in females all traits were statistically different except for bill length

316 (Table 4). Paired differences between geographic groups (comparing each group against

317 the others), revealed that CA and GRO present significant differences in several traits

318 (Table S4).

Species delimitation and divergence times

Three different species hypotheses were assessed: A) species delimited by disjunct

322 populations (groups by geographic region: SMO, GRO, MIA and CHIS), B) phylogroups

323 (SMO/MIA, GRO and CHIS), and C) groups separated by the Isthmus of Tehuantepec (east:

324 SMO/MIA/GRO, and west: CHIS), using different values of $\theta$ priors (population size

325 parameters) to test the sensitivity of the species delimitation results. BP\&P analyses testing

326 the first hypothesis (that allopatric populations are different species) resulted in low

327 statistical support for the split of groups SMO and MIA, and suggested the split of GRO

328 group as a valid species only when using low $\theta$ priors. The high probabilities for an

329 ancestral node suggest splitting into multiple species, as well as the validity of CHIS as an

330 independent group (Fig. 4A). Analysis of the three lineages corresponding to phylogroups

331 resulted in high speciation probabilities in all cases, except when using high $\theta$ priors $(0.01$,

332 IG: 3, 0.02) for the splitting of GRO and SMO/MIA groups (Fig. 4B). Analysis of the two- 
333 lineage hypothesis (i.e. two groups separated by the Isthmus of Tehuantepec) suggested

334 that these groups are separate species (Fig. 4C). Varying the $\theta$ priors affected the resulting

335 speciation probabilities; higher $\theta$ priors resulted in lower probabilities than lower $\theta$ priors.

336 Our divergence time estimates (Fig. 4D) showed that the split between L. rhami complex

337 and its sister group (genus Eugenes) was around 10.55 Mya (8.28-13.14 Mya). The estimate

338 for the first split within the L. rhami complex was dated ca. 0.207 Mya (0.091-0.317 Mya),

339 corresponding to the divergence between populations on either side of the IT. The split

340 between the groups from west of the IT (SMO/MIA and GRO) was dated at $\sim 0.087$ Mya

341 (0.035-0.146 Mya). The independence of groups was supported by high values of posterior

342 probability.

\section{Discussion}

$345 \quad$ Our study provides evidence of high levels of genetic and morphometric

346 differentiation among most of the disjunct populations comprising the L. rhami complex.

347 Our results support the existence of four separate evolutionary lineages: SMO/MIA (rhami),

348 GRO (occidentalis), CHIS (new suggested taxon: tacanensis), and CA (saturatior). The

349 AMOVA and $F_{S T}$ values also indicate the presence of strong population structure between

350 these same geographic regions (e.g. 76.41\% variation among populations). We found

351 significant morphological differences between the southern populations (Honduras and El

352 Salvador), which we expect to be reflected in genetic differentiation, though we were

353 unable to test this hypothesis here due to a lack of tissue samples.

$354 \quad$ Morphometric variation in the 208 specimens of L. rhami also showed geographic

355 structure among the compared areas (four of the five regions were defined a priori). 
356 Although the group sampled in the highlands of Chiapas and Guatemala (CHIS) was the

357 most genetically differentiated, the populations of Guerrero (GRO) and Central America

358 (CA) were the most different in morphometric traits. We had no access to genetic samples

359 from the CA region (Honduras and El Salvador), so we cannot confirm if this morphological

360 variation is consistent at the genetic level. Also, we did not have access to enough voucher

361 specimens from MIA to conduct a reasonable morphological statistical analysis. A larger

362 sampling effort in the southern highlands of Oaxaca (Miahuatlan, Mexico) and in Central

363 America (Honduras and El Salvador) will allow evaluation of species limits in these regions.

364 The genetic variation found in the L. rhami complex corresponds to a phylogenetic

365 discontinuity and a spatial vicariance pattern (Avise et al., 1987) resulting from long-term

366 isolation and/or restricted gene flow among groups, probably promoted by geographic

367 barriers. This pattern of high genetic differentiation is congruent with other studies of

368 Mesoamerican vertebrate species (Barber, 1999; Zarza et al., 2008; Bonaccorso, 2009;

369 Bryson et al., 2011; Smith et al., 2011; Arbeláez-Cortés et al., 2014; Castañeda-Rico et al.,

370 2014). In Trochilidae, high levels of geographic structure have been previously reported,

371 related to differences in current or historical ecological conditions (Adelomyia

372 melanogenys: Chaves et al., 2007; Lampornis amethystinus: Cortés-Rodríguez et al., 2008;

373 Ornelas et al., 2016). Also, moderate levels of differentiation have been found in

374 hummingbird species co-distributed in Mesoamerican cloud forests (Campylopterus

375 curvipennis: González et al., 2011; Amazilia cyanocephala: Rodríguez-Gómez et al., 2013).

376 As expected, the levels of genetic variation were correlated with a pattern of isolation by

377 distance associated with the patchy distribution of cloud forests, where particular

378 environmental characteristics have been reported as drivers of differentiation between 
379 populations (Ramírez-Barahona \& Eguiarte, 2014). In the case of populations from west of 380 the Isthmus of Tehuantepec, geographic structure could be explained by limited gene flow 381 between regions (SMO, MIA and GRO) promoted by isolation by distance. In contrast, the 382 genetic separation between populations on either side of the Isthmus of Tehuantepec is 383 almost certainly influenced by this geographic barrier in addition to distance. Many phylogeography studies have shown the influence of the Isthmus of

385 Tehuantepec as a driver of isolation in Mesoamerican species. This valley in southeastern 386 Mexico is located near three tectonic plates -North American, Cocos and Caribbean387 resulting from different tectonic episodes that took place in the Late Miocene (Barrier, et al. 388 1998). Two main diversification events across the Isthmus of Tehuantepec were detected 389 in the regional bird fauna, placing both events within the Pleistocene (Barber \& Klicka, 390 2010). It is clear that ecological conditions in this area act as a geographic barrier limiting 391 gene flow of L. rhami populations across the Isthmus, and the lack of shared haplotypes 392 across this area demostrates that the Isthmus of Tehuantepec is better considered a hard 393 rather than soft barrier as has been proposed in co-distributed species (e. g. Amazilia 394 cyanocephala; Rodríguez-Gómez et al., 2013). Divergence time estimates show that the split between putative lineages was very 396 recent. The lack of reciprocal monophyly in the multilocus phylogenetic reconstruction

397 (Bayesian inference) may be influenced by low nuclear marker signal due to the temporal 398 scale, resulting in a failure to reconstruct discrete clades in recently evolved species 399 (Knowles \& Carstens, 2007). This signal of ancestral polymorphism and/or incomplete 400 lineage sorting is taken into account in BP\&P estimates, where information of the chosen 401 molecular markers is fully used in closely related species (Yang, 2015). Results of species 
402 delimitation were sensitive to different $\theta$ priors, favoring lumping with higher values, as

403 has been previously reported (McKay et al., 2013). However, splitting of phylogroups was

404 consistently supported in most cases. These findings reveal the potential for recognizing at

405 least three distinct cryptic species, also supported by other criteria evaluated here

406 (morphometric differences, population structure and geographic isolation).

407

Our evaluations of demographic history used different methods (neutrality tests,

408 mismatch distributions and BSP), showing ambiguous patterns of populations dynamics.

409 Range expansion was revealed in the basal group CHIS (Tajima's $D$ and Fu's Fs, mismatch),

410 and subtle population size changes over time were detected by the BSP approach.

411 Additionally, expansion signal was not fully supported in the SMO group, and population

412 stability was found in the youngest clade, GRO. Our divergence time estimates provide

413 evidence of recent Pleistocene diversification of the L. rhami complex, with the first

414 population split occurring in the Isthmus of Tehuantepec (0.207 Mya, 0.091-0.317 Mya),

415 followed by subsequent separation of groups west of the Isthmus, resulting in the splitting

416 of the SMO/MIA and GRO groups (0.087 Mya, 0.07-0.21 Mya). These processes took place

417 during the Pleistocene, when climatic fluctuations resulted in the expansion and

418 contraction of the ranges of highland species, promoting allopatric differentiation (Still et

419 al., 1999). Our estimates of recent splitting support the hypothesis of differentiation

420 promoted by climatic oscillations rather than by older events related to the complex

421 volcanic history of Mexican highlands, such as mountain uplift.

422 Two demographic scenarios for cloud forests species during Pleistocene have been

423 proposed, and they corresponded to the dry refugia and the moist forests hypotheses

424 (Ramírez-Barahona \& Eguiarte, 2013). The dry hypothesis (Haffer, 1969) suggests that 
425 during glacial cycles, climatic oscillations in cloud forests displaced them downslope into

426 refugia, forcing populations to contract their ranges, which subsequently expanded and

427 recolonized them during interglacial cycles. The moist forest hypothesis suggests that

428 unchanging precipitation conditions did not reduce cloud forests into refugia but favored

429 downslope altitudinal migration, where adapted species expanded their ranges during

430 glacial cycles (connectivity), and fragmented them into higher altitudes during interglacial

431 periods. Historical signals of demographic expansion and high levels of structure are more

432 related to dry refugia, while low levels of structure are consistent with moist forest model

433 due to processes of recurrent population connectivity. Therefore, the high levels of genetic

434 structure found in L. rhami are consistent with the dry refugia model. Population dynamics

435 in CHIS were led by down-slope fragmented ranges (glacial cycles) and expanding up-slope

436 (interglacials) revealed by the unimodal distribution of allele differences. In contrast, the

437 SMO and GRO populations show no clear evidence of expansion, and seem to have been

438 maintained in situ, a hyphothesis first supported by the shrub Moussonia deppeana, a

439 Mesoamerican cloud-forest adapted species (Ornelas \& González, 2014).

440 Despite the well-known movement abilities of Trochilidae species, some studies

441 have found that geographical barriers are crucial in promoting high levels of differentiation

442 and the diversification of independent evolutionary lineages in various regions, such as the

443 Andes region (e.g. Adelomyia melanogenys, Chaves \& Smith, 2011), Mesoamerica (Ornelas

444 et al., 2016), the Motagua fault region (Rodríguez-Gómez \& Ornelas, 2014), and the Isthmus

445 of Tehuantepec (Cortés-Rodríguez et al., 2008; González et al., 2011). In contrast, in

446 lowland Neotropical birds, high levels of intraspecific diversification are better explained

447 by the hypothesis of limited dispersal ability (Burney \& Brumfield, 2009). L. rhami exhibits 
448 some altitudinal movements related to the presence of resources available along elevation

449 gradients (Schuchmann \& Boesman, 2018), but long-distance dispersal has not been

450 reported for this species, so both geographic barriers and limited longitudinal and

451 latitudinal dispersal movements could be influencing the geographic separation we

452 observed.

453 Earlier taxonomic studies described different subspecies for this complex: L. $r$.

454 rhami (Lesson, 1839; Peters, 1945), L. r. occidentalis (Phillips, 1966), and L. r. saturatior

455 (Griscom, 1932; Peters, 1945). Our study supports the taxonomic validity of the

456 occidentalis (based on genetic and morphometric data) and saturatior (based on

457 morphometric data) groups. Thus, the suggestion of considering occidentalis and saturatior

458 taxa as races (Schuchmann \& Boesman, 2018) should be reevaluated.

459

The original description of L. r. rhami comprises populations in the highlands of

460 central and southern Mexico, including populations in the state of Guerrero, and

461 populations in Chiapas and Guatemala, which, in agreement with our study, belong to

462 different lineages. Therefore, rhami will just include populations from the Sierra Madre

463 Oriental and the highlands of Oaxaca, while occidentalis belongs to populations distributed

464 in the highlands of Guerrero. Finally, populations in Chiapas and Guatemala belong to a

465 new suggested taxon. The Honduras and El Salvador populations belong to saturatior, for

466 which the differentiation is supported by our morphometric results. Supported by our

467 multilocus phylogenetic approach, by the species delimitation estimates, and by the

468 differences in morphometric traits, we found that L. rhami is a complex formed by four

469 groups that correspond to separate evolutionary lineages and that should be treated as full

470 species. The importance of delimitation of taxonomic units increases given the level of 
471 threat that is reported for the cloud forests of Mesoamerica (resulting from the growth of

472 agricultural and urban areas), and the restricted geographic distribution of L. rhami. The

473 problem of an incorrect placement of subspecies is that this could promote

474 underestimation of biodiversity, and therefore mismanagement in conservation efforts 475 (Zink, 2004).

476

\section{Conclusions}

478

This study presents clear evidence of morphometric and genetic differentiation

479

between populations of the hummingbird Lamprolaima rhami. Pleistocene historical

480

events, the influence of the Isthmus of Tehuantepec as a geographical barrier, and the

481

effects of isolation by distance have shaped the geographical structure found in the L. rhami

482

complex. Contemporary habitat fragmentation and the unique bioclimatic characteristics of

483

cloud forests are probably still influencing this pattern of isolation between populations. In 484 general, we found that species diversity within the L. rhami complex is currently

underestimated, and four taxa should be recognized: 1) populations from the Sierra Madre 486 Oriental and highlands in Oaxaca (rhami), 2) populations from highlands in Guerrero 487 (occidentalis), 3) populations from highlands in Chiapas and Guatemala (new suggested 488 taxon: tacanensis), and 4) populations from highlands in Honduras and El Salvador 489 (saturatior). This study emphasizes the importance of evaluating multiple characters in 490 species complexes that presumably diverged recently or are in an incipient process of 491 speciation. 
494

We thank the Museo de Zoología Alfonso L. Herrera (MZFC, UNAM), Museum of 495 Natural Science (LSU), Museum of Vertebrate Zoology at University of California Berkeley 496 (MVZ), D. Dittman (LSU), C. Cicero (MVZ), and R. Bowie (MVZ) for provided tissues samples 497 and logistical help; The Moore Lab of Zoology at Occidental College (MLZ), Bird and 498 Mammal Collection at the University of California Los Angeles (UCLA), American Museum 499 of Natural History (AMNH), Museum of Comparative Zoology at Harvard University (MCZ), 500 J. McCormack (MLZ), W. Tsai (MLZ), J. Maley (MLZ), K. Molina (UCLA), P. Sweet (AMNH), L. 501 Garetano (AMNH), J. Trimble (MCZ), K. Eldridge (MCZ), for provided assistance and help in 502 carrying out morphological measurements on museum specimens; A. Gordillo, Isabel 503 Vargas, S. Robles, and F. Rebón for technical help; G.F. Calvillo for drawing L. rhami (Figure 504 1), and to all the collectors at MZFC. J. J. Morrone, and C. Cordero provided helpful 505 comments that improved the manuscript. L. Kiere reviewed the English.

506

507 References

508

509

Akaike H. 1987. Factor analysis and AIC. Psychometrika 52: 317-332.

Arbeláez-Cortés E, Navarro-Sigüenza AG. 2013. Molecular evidence of the taxonomic

510 status of western Mexican populations of Phaethornis longirostris (Aves: Trochilidae).

511 Zootaxa 3716: 81-97.

512

Arbeláez-Cortés E, Roldán-Piña D, Navarro-Sigüenza AG. 2014. Multilocus

513 phylogeography and morphology give insights into the recent evolution of a Mexican

514 endemic songbird: Vireo hypochryseus. Journal of Avian Biology 45: 253-263. 
Arévalo E, Davis SK, Sites JW. 1994. Mitochondrial DNA sequence divergence and

516 phylogenetic relationships among eight chromosome races of the Sceloporus grammicus

517 complex (Phrynosomatidae) in central Mexico. Systematic Biology 43: 387-418.

518

Ataroff M, Rada F. 2000. Deforestation impact on water dynamics in a Venezuelan

\section{9}

Andean cloud forest. AMBIO: A Journal of the Human Environment 29: 440-444.

520

Avise JC, Arnold J, Ball RM, Bermingham E, Lamb T, Neigel JE, Reeb CA, Saunders NC.

521 1987. Intraspecific Phylogeography: The Mitochondrial DNA Bridge Between Population

522 Genetics and Systematics. Annual Review of Ecology and Systematics 18: 489-522.

523

Barber PH. 1999. Patterns of gene flow and population genetic structure in the

524 canyon treefrog, Hyla arenicolor (Cope). Molecular Ecology 8: 563-576.

525 Barber BR, Klicka J. 2010. Two pulses of diversification across the Isthmus of

526 Tehuantepec in a montane Mexican bird fauna. Proceedings of the Royal Society of London B:

527 Biological Sciences, rspb20100343.

528 Barrier E, Velasquillo L, Chavez M, Gaulon R. 1998. Neotectonic evolution of the

529 Isthmus of Tehuantepec (southeastern Mexico). Tectonophysics, 287(1-4), 77-96.

530

Bauer DF. 1972. Constructing confidence sets using rank statistics. Journal of the

531 American Statistical Association 67: 687-690.

Bleiweiss R. 1998a. Slow rate of molecular evolution in high-elevation

533 hummingbirds. Proceedings of the National Academy of Sciences 95: 612-616.

534 Bleiweiss R. 1998b. Tempo and mode of hummingbird evolution. Biological Journal

535 of the Linnean Society 65: 63-76. 
Bonaccorso E. 2009. Historical biogeography and speciation in the Neotropical

537 highlands: molecular phylogenetics of the jay genus Cyanolyca. Molecular Phylogenetics and 538 Evolution 50: 618-632.

Bonaccorso E, Navarro-Sigüenza AG, Sánchez-González LA, Townsend AP,

540 García-Moreno J. 2008. Genetic differentiation of the Chlorospingus ophthalmicus complex

541 in Mexico and Central America. Journal of Avian Biology 39: 311-321.

542 Bonnet E, de Peer YV. 2002. zt: a software tool for simple and partial Mantel tests.

543 Journal of Statistical Software 7: 1-12.

544 Bryson RW, Murphy RW, Lathrop A, Lazcano-Villareal D. 2011. Evolutionary drivers

545 of phylogeographical diversity in the highlands of Mexico: a case study of the Crotalus

546 triseriatus species group of montane rattlesnakes. Journal of Biogeography 38: 697-710.

547 Burney CW, Brumfield RT. 2009. Ecology predicts levels of genetic differentiation in

548 Neotropical birds. The American Naturalist 174: 358-368.

549 Castañeda-Rico S, León-Paniagua L, Vázquez-Domínguez E, Navarro-Sigüenza AG.

550 2014. Evolutionary diversification and speciation in rodents of the Mexican lowlands: The

551 Peromyscus melanophrys species group. Molecular phylogenetics and evolution 70: 454-463.

552 Chaves JA, Pollinger JP, Smith TB, LeBuhn G. 2007. The role of geography and

553 ecology in shaping the phylogeography of the speckled hummingbird (Adelomyia

554 melanogenys) in Ecuador. Molecular Phylogenetics and Evolution 43: 795-807.

555 Chaves JA, Smith TB. 2011. Evolutionary patterns of diversification in the Andean

556 hummingbird genus Adelomyia. Molecular Phylogenetics and Evolution 60: 207-218.

557 Clement M, Posada D, Crandall KA. 2000. TCS: a computer program to estimate gene 558 genealogies. Molecular ecology 9: 1657-1659. 
560 García-Moreno J. 2008. Phylogeography and population genetics of the Amethyst-throated

561 Hummingbird (Lampornis amethystinus). Molecular Phylogenetics and Evolution 48: 1-11.

562

de Barcellos Falkenberg D, Voltolini JC. 1995. The montane cloud forest in southern

563 Brazil. Tropical Montane cloud forests: 138-149.

564 Drummond AJ, Rambaut A. 2007. BEAST: Bayesian evolutionary analysis by

565 sampling trees. BMC Evolutionary Biology 7: 214.

566 Drummond AJ, Rambaut A, Shapiro B, Pybus OG. 2005. Bayesian coalescent

567 inference of past population dynamics from molecular sequences. Molecular Biology and

568 Evolution 22: 1185-1192.

569 Eberhard JR, Bermingham E, Zink R. 2004. Phylogeny and biogeography of the

570 Amazona ochrocephala (Aves: Psittacidae) complex. The Auk 121: 318-332.

571 Excoffier L, Laval G, Schneider S. 2005. Arlequin (version 3.0): an integrated

572 software package for population genetics data analysis. Evolutionary Bioinformatics Online 573 1: 47-50.

574 Excoffier L, Smouse PE, Quattro JM. 1992. Analysis of molecular variance inferred 575 from metric distances among DNA haplotypes: application to human mitochondrial DNA 576 restriction data. Genetics 131: 479-491.

577 Foster P. 2001. The potential negative impacts of global climate change on tropical 578 montane cloud forests. Earth-Science Reviews 55: 73-106.

579 González C, Ornelas JF, Gutiérrez-Rodríguez C. 2011. Selection and geographic 580 isolation influence hummingbird speciation: genetic, acoustic and morphological 
581 divergence in the wedge-tailed sabrewing (Campylopterus curvipennis). BMC Evolutionary

582 Biology 11: 38.

583 González-Rodríguez A, Bain J, Golden J, Oyama K. 2004. Chloroplast DNA variation in

584 the Quercus affinis-Q. laurina complex in Mexico: geographical structure and associations

585 with nuclear and morphological variation. Molecular Ecology 13: 3467-3476.

586 Griscom L. 1932. New birds from Honduras and Mexico. Proceedings New England

587 Zoological Club: 53-62.

588 Gross J, Ligges U. 2015. nortest: Tests for Normality. R package version 1.0-4.

589 http://CRAN.R-project.org/package=nortest

590 Haffer J. 1969. Speciation in Amazonian forest birds. Science 165: 131-137.

591 Hamilton LS. 1995. Mountain cloud forest conservation and research: a synopsis.

592 Mountain Research and Development: 259-266.

593 Harpending HC. 1994. Signature of ancient population growth in a low-resolution

594 mitochondrial DNA mismatch distribution. Human Biology 66: 591-600.

595 Heled J, Drummond AJ. 2010. Bayesian inference of species trees from multilocus 596 data. Molecular Biology and Evolution 27: 570-580.

597 Hollander M, Wolfe DA. 1973. Nonparametric Statistical Methods. New York: John 598 Wiley \& Sons. Pages 115-120.

599 Howell NG, Webb S. 1995. A guide to the birds of Mexico and Northern Central 600 America. Oxford: Oxford University Press.

601 Huelsenbeck J, Ronquist F. 2002. MrBayes 3: Bayesian analysis of phylogeny. 602 Computer program distributed by the authors. Department of Ecology, Behavior and 603 Evolution, University of California. 
606 Sciences, rspb20100662.

607

Lerner HR, Meyer M, James HF, Hofreiter M, Fleischer RC. 2011. Multilocus

608

resolution of phylogeny and timescale in the extant adaptive radiation of Hawaiian

honeycreepers. Current Biology 21: 1838-1844.

610

Lesson. 1839. Rev. Zool. Paris. 315.

611

Martínez-Morales MA. 2005. Landscape patterns influencing bird assemblages in a

612 fragmented neotropical cloud forest. Biological Conservation 121: 117-126.

614 highlands of Mexico: genetic and phenotypic divergence in the Mexican jay (Aphelocoma ultramarina). Molecular Ecology 17: 2505-2521.

McGuire JA, Witt CC, Altshuler DL, Remsen JVJr. 2007. Phylogenetic systematics and

617 biogeography of hummingbirds: Bayesian and maximum likelihood analyses of partitioned 618 data and selection of an appropriate partitioning strategy. Systematics and Biology 56: 837619856.

McGuire JA, Witt CC, Remsen JVJr, Corl A, Rabosky DL, Alshuler DL, Dudley R.

623 McKay BD, Mays Jr. HL, Wu Y, Li H, Yao CT, Nishiumi I, Zou F. 2013. An empirical 624 comparison of character-based and coalescent-based approaches to species delimitation in a 625 young avian complex. Molecular Ecology 22: 4943-4957. 
627 378(1): 1-110.

628 Mulligan M. 2010. Modeling the tropics-wide extent and distribution of cloud forest 629 and cloud forest loss, with implications for conservation priority. Tropical Montane Cloud 630 Forests: Science for Conservation and Management: 14-38.

631 Olander LP, Scatena F, Silver WL. 1998. Impacts of disturbance initiated by road 632 construction in a subtropical cloud forest in the Luquillo Experimental Forest, Puerto Rico. 633 Forest Ecology and Management 109: 33-49.

634 Ornelas JF, González C. 2014. Interglacial genetic diversification of Moussonia 635 deppeana (Gesneriaceae), a hummingbird-pollinated, cloud forest shrub in northern 636 Mesoamerica. Molecular Ecology 23: 4119-4136.

637 Ornelas JF, González C, Hernández-Baños BE, García-Moreno J. 2016. Molecular and 638 iridescent feather reflectance data reveal recent genetic diversification and phenotypic 639 differentiation in a cloud forest hummingbird. Ecology and Evolution 6(4):1104-1127. 640 Ornelas JF, Ruiz-Sánchez E, Sosa V. 2010. Phylogeography of Podocarpus matudae 641 (Podocarpaceae): pre-Quaternary relicts in northern Mesoamerican cloud forests. Journal 642 of biogeography 37: 2384-2396.

643 Ornelas JF, Sosa V, Soltis DE, Daza JM, González C, Soltis PS, Gutiérrez-Rodríguez C, 644 de los Monteros AE, Castoe TA, Bell C. 2013. Comparative phylogeographic analyses 645 illustrate the complex evolutionary history of threatened cloud forests of northern 646 Mesoamerica. Public Library of Science ONE 8(2): e56283. 
Pacheco MA, Battistuzzi FU, Lentino M, Aguilar RF, Kumar S, Escalante AA. 2011.

648 Evolution of modern birds revealed by mitogenomics: timing the radiation and origin of 649 major orders. Molecular Biology and Evolution 28: 1927-1942.

650 Peters JL. 1945. Check-List of Birds of the World. Cambridge, Harvard University

651 Press. 83-84.

652

Phillips, 1966. Further systematic notes on Mexican birds. Bulletin of the British

653 Ornithologists' Club 86(6): 103-112.

654

Posada D. 2008. jModelTest: phylogenetic model averaging. Molecular Biology and

655 Evolution 25: 1253-1256.

656

Prychitko TM, Moore WS. 1997. The utility of DNA sequences of an intron from the

$657 \beta$-fibrinogen gene in phylogenetic analysis of woodpeckers (Aves: Picidae). Molecular

658

phylogenetics and evolution 8: 193-204.

659

Rambaut A, Suchard M, Drummond A. 2013. Tracer v1. 6.0.

660

Rambaut, A. \& Drummond, A. (2007) TreeAnnotator. Available from:

661 http://beast.bio.ed.ac.uk/TreeAnnotator.

662

Ramírez-Barahona S, Eguiarte LE. 2013. The role of glacial cycles in promoting

663 genetic diversity in the Neotropics: the case of cloud forests during the Last Glacial

664 Maximum. Ecology and Evolution 3(3): 725-738.

665 Ramírez-Barahona S, Eguiarte LE. 2014. Changes in the distribution of cloud forests

666 during the last glacial predict the patterns of genetic diversity and demographic history of

667 the tree fern Alsophila firma (Cyatheaceae). Journal of Biogeography 41: 2396-2407.

668

Rannala B, Yang Z. 2003. Bayes estimation of species divergence times and ancestral

669 population sizes using DNA sequences from multiple loci. Genetics 164: 1645-1656. 
671 delimitation. Genetics 194: 245-253.

672 Rannala B, Yang Z. 2017. Efficient Bayesian species tree inference under the

673 multispecies coalescent. Systematics Biology 66:823-842.

674 Ríos-Muñoz CA. 2013. ¿Es posible reconocer una unidad biótica entre América del

675 Norte y del Sur? Revista mexicana de biodiversidad 84: i-ix.

676 Rodríguez-Gómez F, Gutiérrez-Rodríguez C, Ornelas JF. 2013. Genetic, phenotypic

677 and ecological divergence with gene flow at the Isthmus of Tehuantepec: the case of the 678 azure-crowned hummingbird (Amazilia cyanocephala). Journal of Biogeography $67940(7): 1360-1373$.

680 Rodríguez-Gómez F, Ornelas JF. 2014. Genetic divergence of the Mesoamerican

681 azure-crowned hummingbird (Amazilia cyanocephala, Trochilidae) across the

682 Motagua-Polochic-Jocotán fault system. Journal of Zoological Systematics and Evolutionary 683 Research 52: 142-153.

Rogers AR, Harpending H. 1992. Population growth makes waves in the distribution 685 of pairwise genetic differences. Molecular Biology and Evolution 9: 552-569.

RStudio Team. 2016. RStudio: Integrated Development for R. RStudio, Inc., Boston, 687 MA, URL http://www.rstudio.com/. rhami). In: del Hoyo J, Elliot A, Sargatal J, Christie DA, Juana E (eds.). Handbook of the Birds 690 of the World Alive . Lynx Edicions, Barcelona.(retrieved

691 from https://www.hbw.com/node/55526 on 19 February 2018). 
692

Slatkin M, Hudson RR. 1991. Pairwise comparisons of mitochondrial DNA sequences

693 in stable and exponentially growing populations. Genetics 129: 555-562.

694

Smith BT, Escalante P, Hernández-Baños BE, Navarro-Sigüenza AG, Rohwer S, Klicka

695

J. 2011. The role of historical and contemporary processes on phylogeographic structure 696 and genetic diversity in the Northern Cardinal, Cardinalis cardinalis. BMC Evolutionary

697 Biology 11: 136.

698

Sorenson MD, Ast JC, Dimcheff DE, Yuri T, Mindell DP. 1999. Primers for a PCR-based 699 approach to mitochondrial genome sequencing in birds and other vertebrates. Molecular

700

Phylogenetics and Evolution 12: 105-114.

701

StatSoft I. 2004. STATISTICA (data analysis software system), version 7. Available at

702 http://www.statsoft.com

703

Still CJ, Foster PN, Schneider SH. 1999. Simulating the effects of climate change on

704 tropical montane cloud forests. Nature 398: 608-610.

705

Williams LJ, Abdi H. 2010. Fisher's least significant difference (LSD) test.

706 Encyclopedia of research design: 1-5.

707

Yang Z. 2015. The BPP program for species tree estimation and species delimitation.

708 Current Zoology 61(5): 854-865.

709

Yang Z, Rannala B. 2010. Bayesian species delimitation using multilocus sequence

710 data. Proceedings of the National Academy of Sciences 107(20): 9264-9269.

711

Yang Z, Rannala B. 2014. Unguided species delimitation using DNA sequence data

712 from multiple loci. Molecular Biology and Evolution 31: 3125-3135. 
714 evidence for more than one species within Eugenes fulgens (Aves: Trochilidae). Molecular 715 phylogenetics and evolution 90: 80-84.

716 Zarza E, Reynoso VH, Emerson BC. 2008. Diversification in the northern neotropics:

717 mitochondrial and nuclear DNA phylogeography of the iguana Ctenosaura pectinata and 718 related species. Molecular Ecology 17: 3259-3275.

719 Zink RM. 2004. The role of subspecies in obscuring avian biological diversity and 720 misleading conservation policy. Proceedings of the Royal Society of London B: Biological 721 Sciences 271 561-564.

722 


\section{Figure 1}

Geographic distribution of the Lamprolaima rhami complex

Geographic distribution of the Lamprolaima rhami complex. Hexagons represent sampled localities corresponding to tissues used in this study. Geographic groups defined a priori are drawn in different colors. Geographic groups: Sierra Madre Oriental (SMO, blue), highlands of Guerrero (GRO, green), Sierra of Miahuatlan in Oaxaca (MIA, yellow), highlands of Chiapas and Guatemala (CHIS, red), highlands of Honduras and El Salvador, Cental America (CA, purple). The statistical parsimony haplotype network for 54 individuals of $L$. rhami constructed with concatenated mtDNA dataset (ATPase 6 and 8, and control region) is shown above the map. The size of each circle is proportional to the number of individuals carrying each haplotype. Illustration of L. rhami by Giselle Fernanda Calvillo García. 


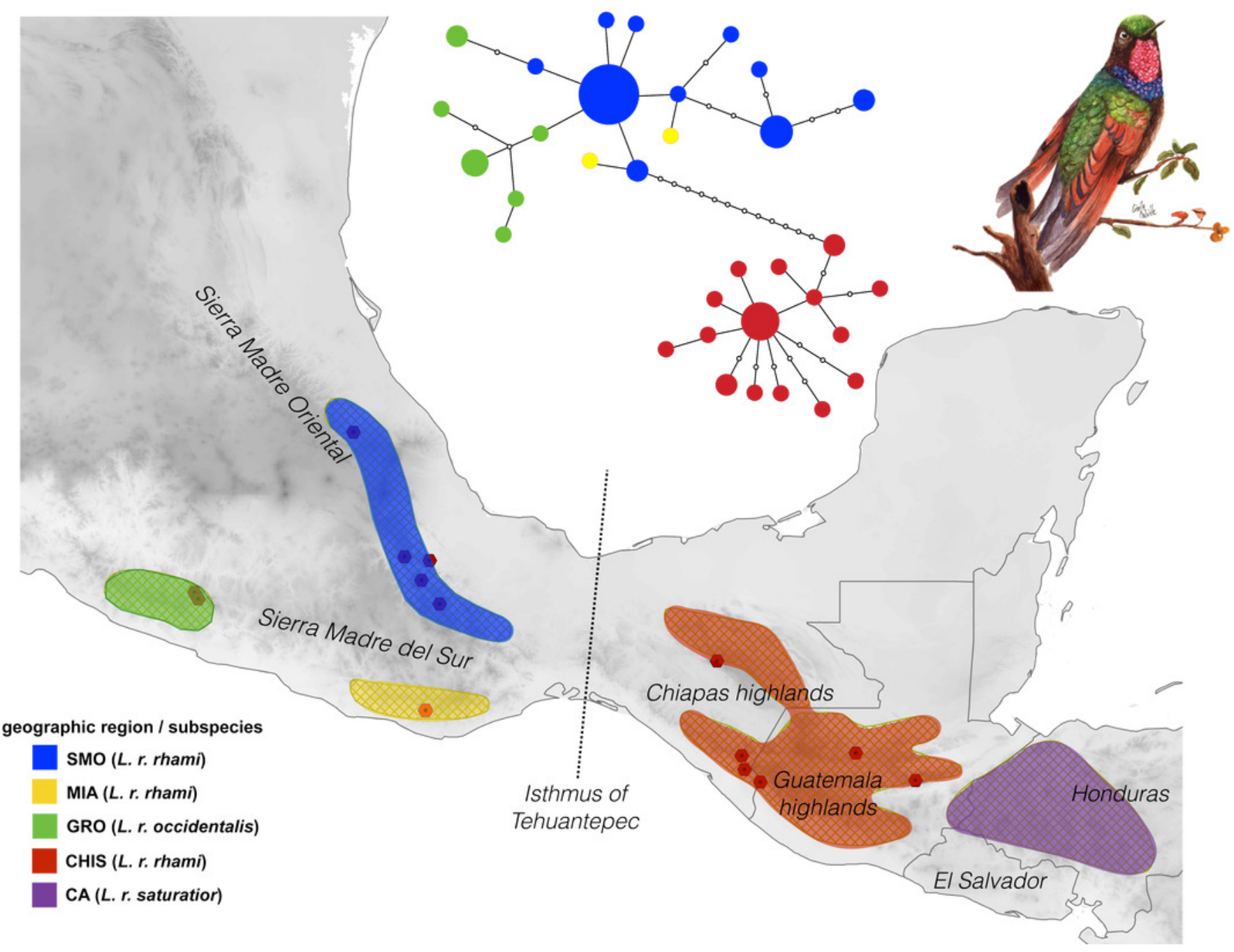




\section{Figure 2}

Mismatch distribution and Bayesian skyline plots

Mismatch distributions and Bayesian skyline plots for three geographic groups (A. Sierra Madre Oriental, SMO; B. highlands of Guerrero, GRO; C. highlands of Chiapas and Guatemala, CHIS) of L. rhami (mtDNA: CR, ATPase 6 and 8). In mismatch distributions, solid lines indicate the observed distributions of pairwise differences, and dotted lines represent simulated distributions under a model of population expansion. In Bayesian skyline plots, solid lines represent median estimates and shaded areas represent 95\% confidence intervals.
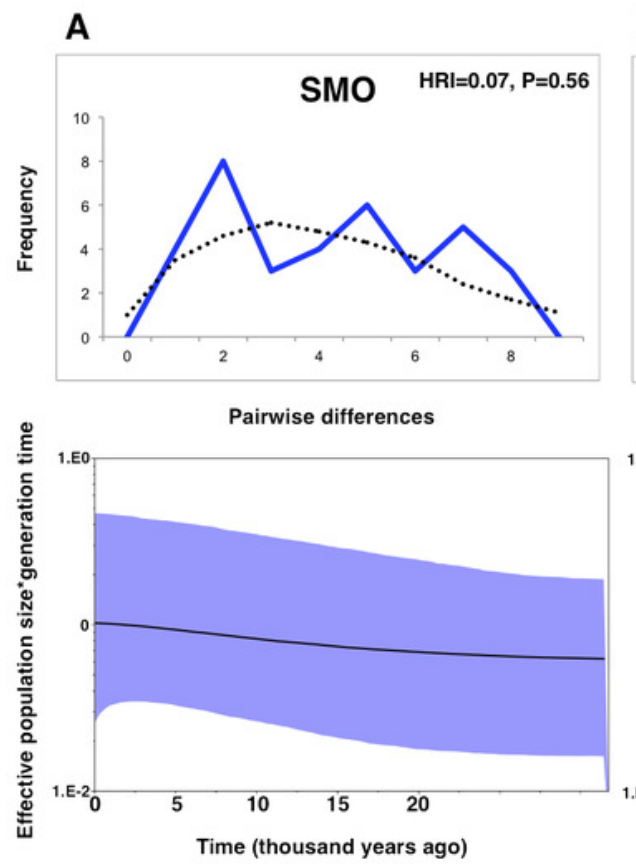

B

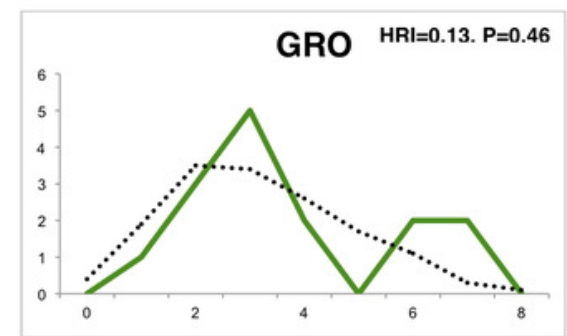

Pairwise differences

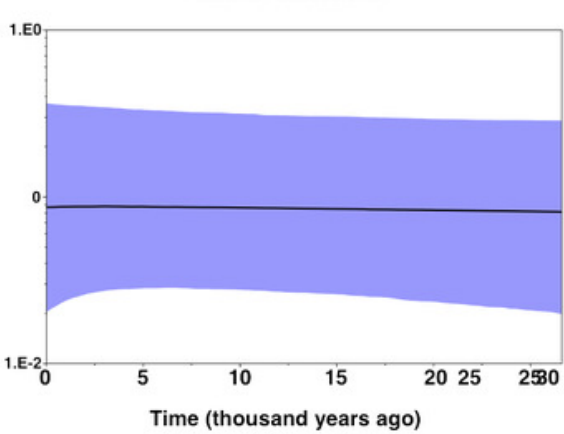

C

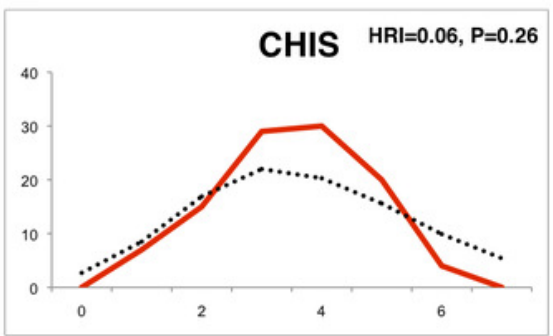

Pairwise differences

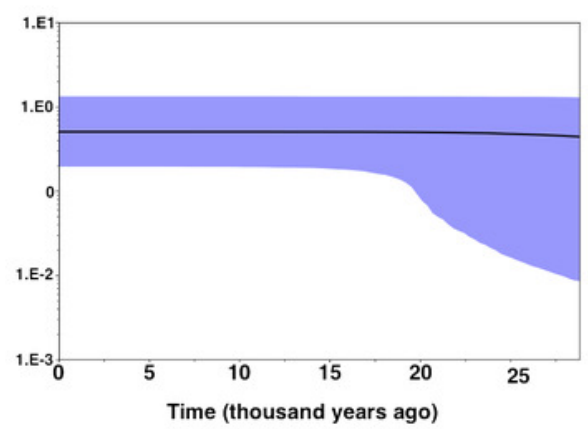


Figure 3 (on next page)

Phylogenetic Bayesian Inference

Phylogenetic Bayesian Inference reconstruction of 31 individuals from the $L$. rhami complex using mitochondrial and nuclear markers (ATPase 6 and 8, CR, ND2, ND4, MUSK, BFib, ODC, and AK1). Posterior probabilities PP $>0.95$ are shown $(*)$. Different colors represent different groups according to the geographic regions defined a priori (see Figure 1 legend). 


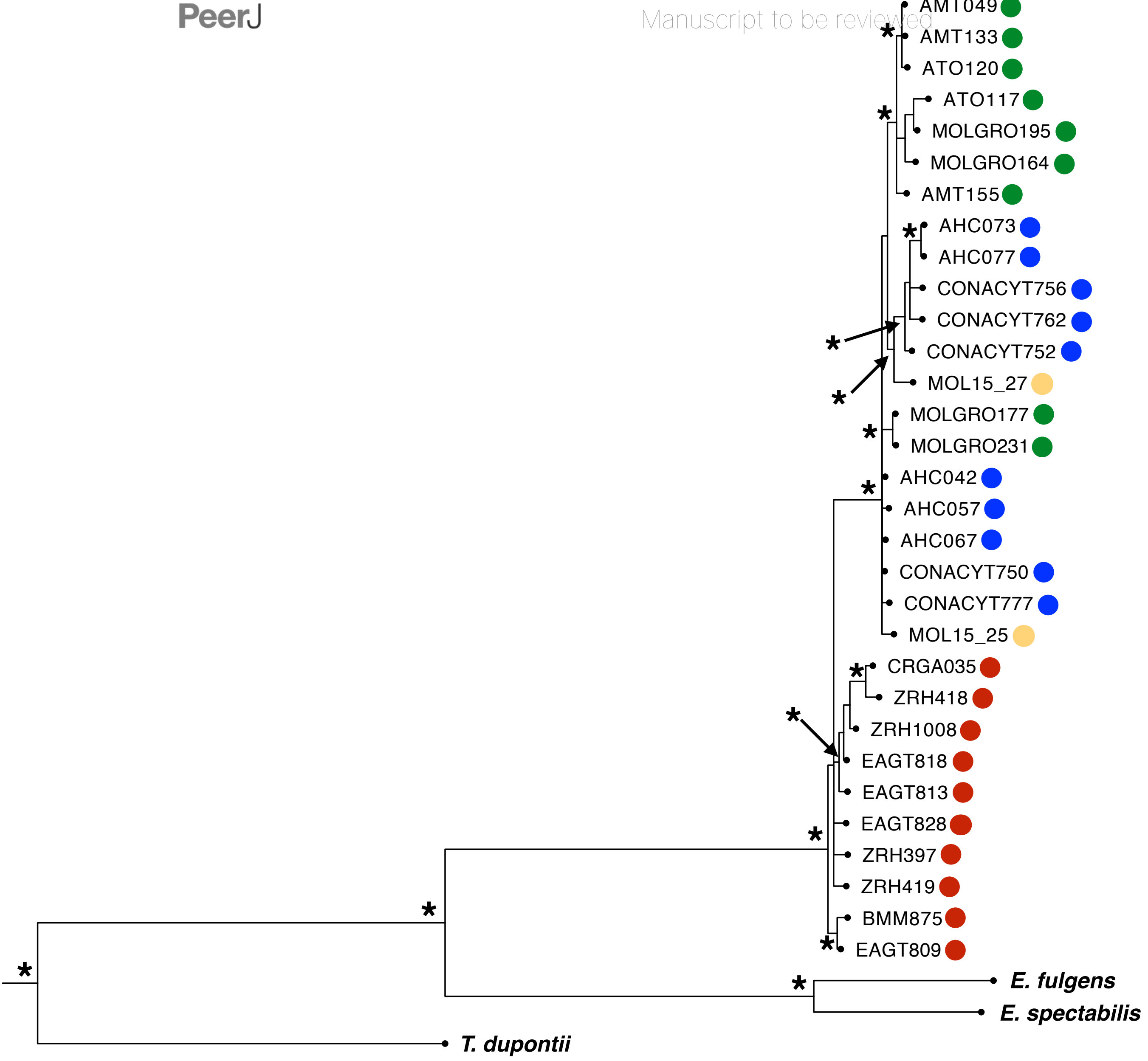




\section{Figure 4 (on next page)}

Species delimitation and divergence times

Results from a coalescent-based species delimitation analysis implemented in Bayesian Phylogenetics and Phylogeography (BP\&P) of three possible hypotheses based on: $(A)$ disjunct populations (groups by geographic region: SMO, GRO, MIA, CHIS), (B) DNA groups (SMO/MIA, GRO, CHIS), and (C) groups separated by the Isthmus of Tehuantepec (east: SMO/MIA/GRO, and west: CHIS). Speciation probabilities for each node are shown in boxes: top, low $\theta$ prior (0.0001); middle, medium q prior (0.001); bottom, high q prior (0.01). * Indicates statistical support for splitting (posterior probabilities of 0.95 or higher). (D) Divergence times and Bayesian species tree topology (*BEAST) for L. rhami complex, bars on each node represent $95 \%$ of high posterior densities of divergence times (HPD), Mya (Million years ago). Posterior probabilities are shown below node ages. 
(A)

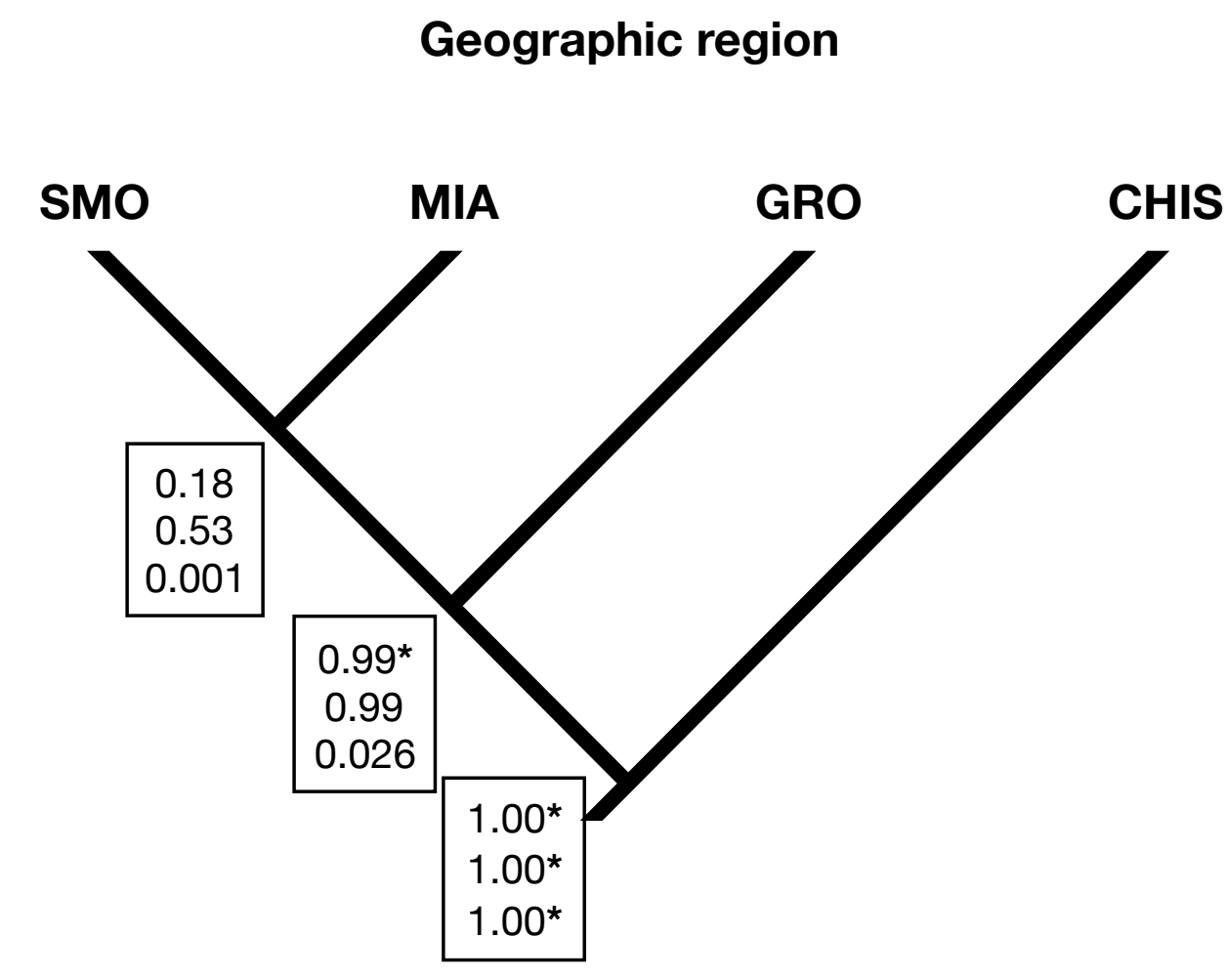

(B)

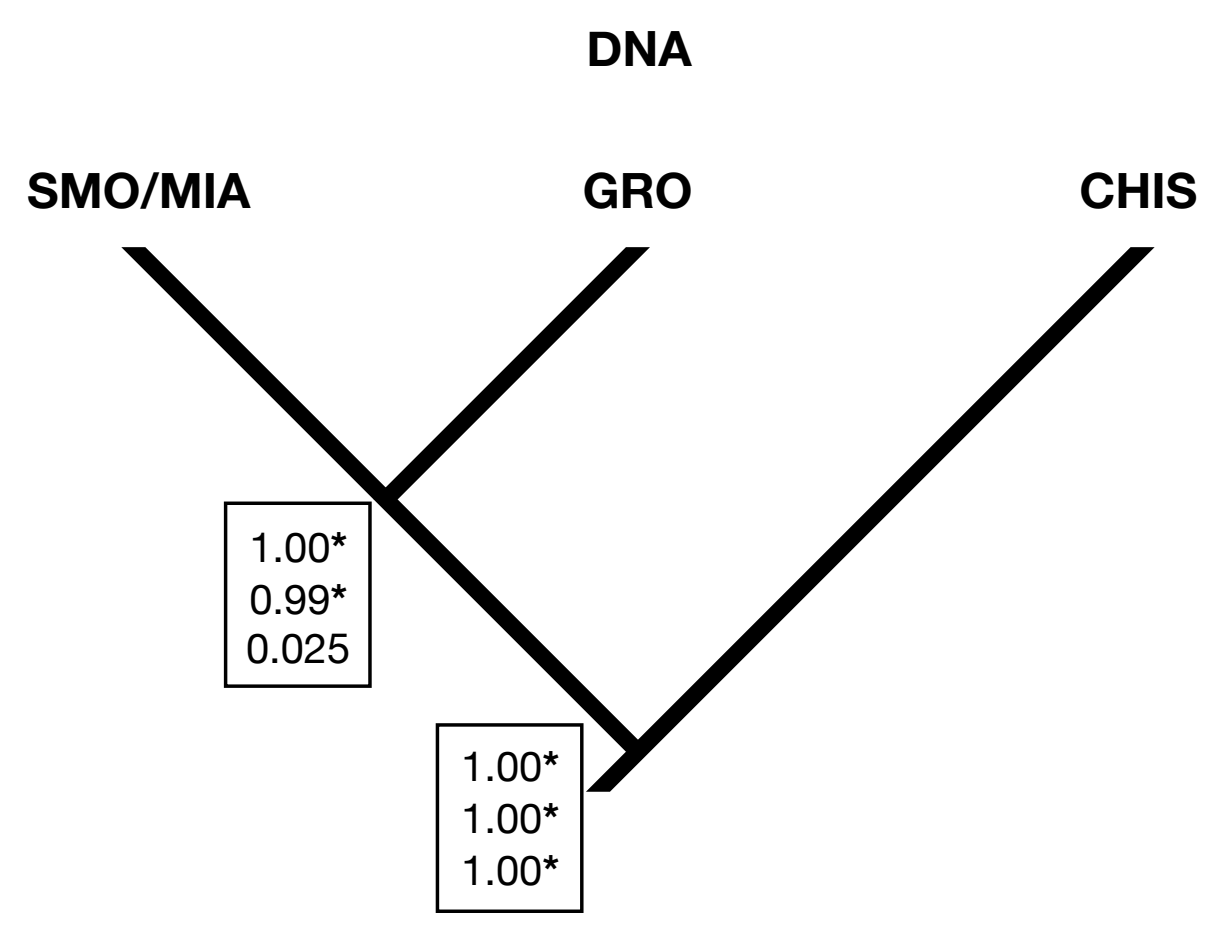

Manuscript to be reviewed

(C)

Isthmus of Tehuantepec

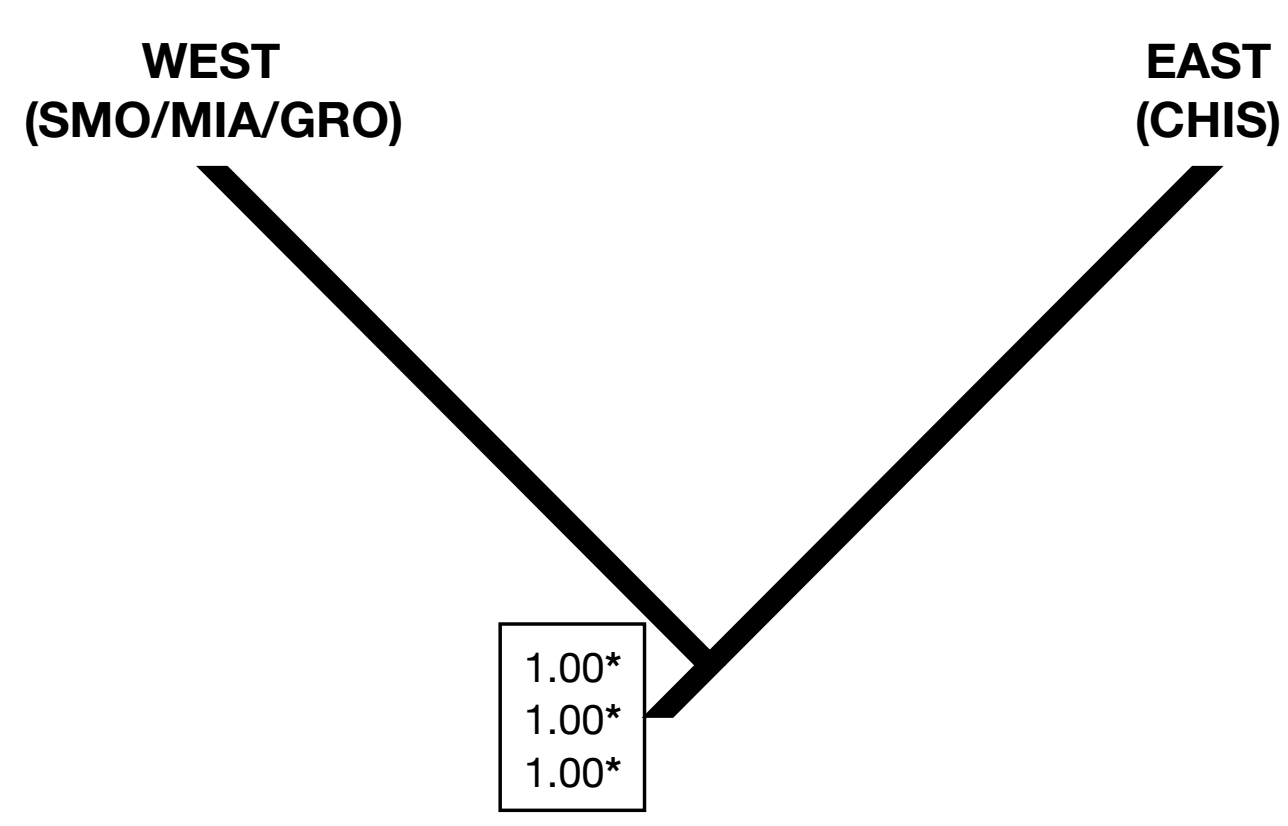

(D)

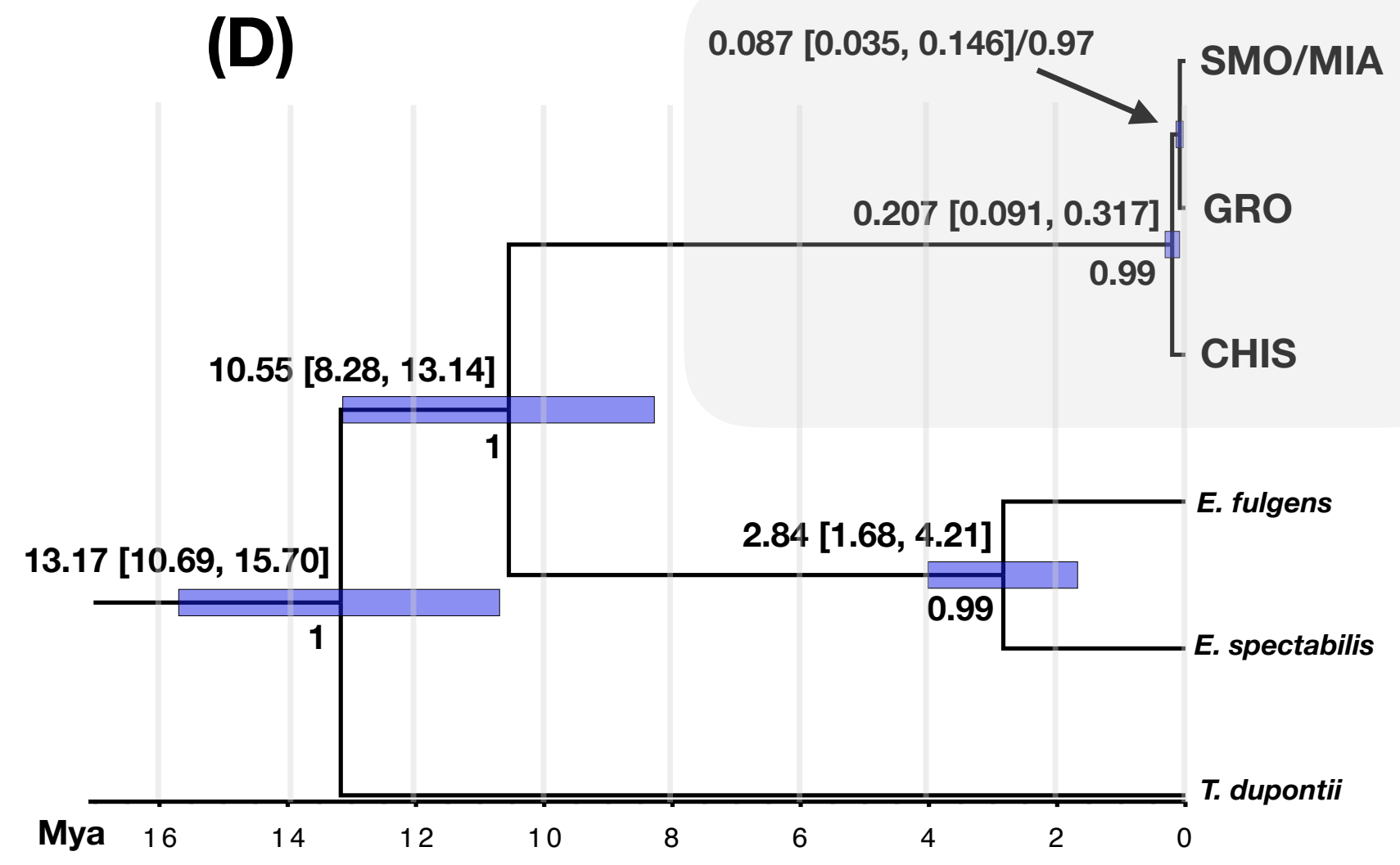




\section{Table $\mathbf{1}$ (on next page)}

Statistical parameters

Statistical parameters of genetic diversity, population structure and population demography for mtDNA (CR, ATPase 6 and 8). n: number of sequences used, h: number of haplotypes, $\mathrm{Hd}$ : haplotype diversity, $\pi$ : nucleotide diversity, Pi: mean number of pairwise differences. ${ }^{*} p$-value $<0.05,{ }^{* *} p$-value $<0.01 .{ }^{* * *} p$-value $<0.001$. 
1 Statistical parameters of genetic diversity, population structure and population demography for 2 mtDNA (CR, ATPase 6 and 8). n: number of sequences used, h: number of haplotypes, Hd:

3 haplotype diversity, $\pi$ : nucleotide diversity, Pi: mean number of pairwise differences. ${ }^{*} p$ -

4 value $<0.05,{ }^{* *} p$-value $<0.01{ }^{* * *} p$-value $<0.001$.

5

\begin{tabular}{|l|l|l|l|l|l|l|l|}
\hline GROUP & $\mathbf{n}$ & $\mathbf{h}$ & Hd & $\boldsymbol{\pi}$ & $\mathbf{P i}($ theta) & Tajima's D & Fu's Fs Test \\
\hline SMO & 22 & 9 & 0.81 & 0.0022 & 4.22 & -0.559 & $-5.505^{* *}$ \\
\hline GRO & 9 & 6 & 0.89 & 0.0026 & 3.73 & -0.886 & $-2.77^{*}$ \\
\hline CHIS & 21 & 15 & 0.94 & 0.0021 & 3.50 & $-1.988^{*}$ & $-14.93^{* * *}$ \\
\hline
\end{tabular}

6

7 


\section{Table 2 (on next page)}

Population pairwise

Population pairwise $F_{S T}$ mtDNA (CR, ATPase 6 and 8 ). ${ }^{*} p$-value $<0.05$. 
1 Population pairwise $F_{S T} \operatorname{mtDNA}(\mathrm{CR}, \mathrm{ATPase} 6$ and 8$) .{ }^{*} p$-value $<0.05$.

2

\begin{tabular}{|l|l|l|l|}
\hline & SMO & GRO & CHIS \\
\hline SMO & --- & & \\
\hline GRO & $0.176^{*}$ & ---- & \\
\hline CHIS & $0.769^{*}$ & $0.784^{*}$ & ---- \\
\hline
\end{tabular}

3

4

5 


\section{Table 3(on next page)}

\section{AMOVA results}

AMOVA results on Lamprolaima rhami populations defined according to geographic groups, and groups on either side of the Isthmus of Tehuantepec using mtDNA (CR, ATPase 6 and 8). $* * * p$-value $<0.0001$. 
1 AMOVA results on Lamprolaima rhami populations defined according to geographic groups, 2 and groups on either side of the Isthmus of Tehuantepec using mtDNA (CR, ATPase 6 and 8). $3 * * * p$-value $<0.0001$.

4

\begin{tabular}{|c|c|c|c|c|c|}
\hline & d.f. & $\begin{array}{c}\text { Sum of } \\
\text { squares }\end{array}$ & $\begin{array}{c}\text { Variance } \\
\text { components }\end{array}$ & $\begin{array}{c}\text { Percentage of } \\
\text { variation }\end{array}$ & $\begin{array}{c}\text { Fixation } \\
\text { indices }\end{array}$ \\
\hline Geographic groups (a priori) & \multicolumn{2}{|l|}{} \\
\hline $\begin{array}{c}\text { Among } \\
\text { populations }\end{array}$ & 2 & 167.63 & 5.04 & 76.41 & \\
\hline $\begin{array}{c}\text { Within } \\
\text { populations }\end{array}$ & 49 & 76.23 & 1.56 & 23.59 & $F_{S T}=0.76^{* * *}$ \\
\hline Total & 51 & 243.87 & 6.59 & & \\
\hline
\end{tabular}

Groups on either side of the Isthmus of Tehuantepec

\begin{tabular}{|c|c|c|c|c|c|}
\hline $\begin{array}{c}\text { Among } \\
\text { populations }\end{array}$ & 1 & 159.05 & 6.28 & 78.74 & \\
\hline $\begin{array}{c}\text { Within } \\
\text { populations }\end{array}$ & 50 & 84.82 & 1.70 & 21.26 & \\
\hline Total & 51 & 243.86 & 7.98 & & $F_{S T}=0.79 * * *$ \\
\hline
\end{tabular}

5

6 


\section{Table 4(on next page)}

Multiple Kruskall-Wallis tests

Multiple Kruskall-Wallis tests to evaluate differences between groups: a) by geographic region (SMO, GRO, CHIS, CA), and b) by groups on either side of the Isthmus of Tehuantepec (IT, east and west). 
1 Multiple Kruskall-Wallis tests to evaluate differences between groups: a) by geographic 2 region (SMO, GRO, CHIS, CA), and b) by groups on either side of the Isthmus of Tehuantepec 3 (IT, east and west).

4

5

\begin{tabular}{|c|c|c|c|c|c|c|c|}
\hline & \multicolumn{3}{|c|}{ a) Geographic region } & \multicolumn{3}{|l|}{ b) IT } \\
\hline & & $\chi^{2}$ & $\begin{array}{l}d \\
f\end{array}$ & $p$-value & $\chi^{2}$ & $\begin{array}{l}d \\
f\end{array}$ & $p$-value \\
\hline \multirow[t]{5}{*}{ MALES } & Bill length & $\begin{array}{l}7.866 \\
1\end{array}$ & 3 & 0.04886 & 1.6847 & 1 & 0.1943 \\
\hline & Bill width & $\begin{array}{l}19.38 \\
6\end{array}$ & 3 & $\begin{array}{l}0.00022 \\
75\end{array}$ & 6.3669 & 1 & $\begin{array}{l}0.0116 \\
3\end{array}$ \\
\hline & Bill depth & $\begin{array}{l}26.42 \\
5 \\
\end{array}$ & 3 & 7.77E-06 & $\begin{array}{l}0.9171 \\
9 \\
\end{array}$ & 1 & 0.3382 \\
\hline & $\begin{array}{l}\text { Wing } \\
\text { chord }\end{array}$ & 19.14 & 3 & $\begin{array}{l}0.00025 \\
58\end{array}$ & 8.0642 & 1 & $\begin{array}{l}0.0045 \\
15\end{array}$ \\
\hline & Tail length & $\begin{array}{l}16.98 \\
2\end{array}$ & 3 & $\begin{array}{l}0.00071 \\
27\end{array}$ & 1.834 & 1 & 0.1757 \\
\hline \multirow[t]{5}{*}{ FEMALES } & Bill length & $\begin{array}{l}9.442 \\
1\end{array}$ & 3 & 0.02396 & $\begin{array}{l}0.4084 \\
5\end{array}$ & 1 & 0.5228 \\
\hline & Bill width & $\begin{array}{l}13.12 \\
5\end{array}$ & 3 & $\begin{array}{l}0.00437 \\
4\end{array}$ & 6.346 & 1 & $\begin{array}{l}0.0117 \\
6\end{array}$ \\
\hline & Bill depth & $\begin{array}{l}20.15 \\
9\end{array}$ & 3 & $\begin{array}{l}0.00015 \\
74\end{array}$ & 5.3064 & 1 & $\begin{array}{l}0.0212 \\
5\end{array}$ \\
\hline & $\begin{array}{l}\text { Wing } \\
\text { chord }\end{array}$ & $\begin{array}{l}29.69 \\
8\end{array}$ & 3 & $1.60 \mathrm{E}-06$ & 18.547 & 1 & $\begin{array}{l}1.66 \mathrm{E}- \\
05\end{array}$ \\
\hline & Tail length & $\begin{array}{l}28.09 \\
2\end{array}$ & 3 & 3.48E-06 & 10.168 & 1 & $\begin{array}{l}0.0014 \\
29 \\
\end{array}$ \\
\hline
\end{tabular}

6 